\title{
Research of the stress-strain state of reinforced concrete beamless floor
}

\author{
Ilshat Mirsayapov ${ }^{1[0000-0003-4902-6167]}, \quad$ Evgeny $\quad$ Khorkov $^{1[0000-0001-9040-6538]}$, and \\ Rustam Minzianov*1[0000-0002-7198-9907] \\ ${ }^{1}$ Kazan State University of Architecture and Engineering, 420043 Kazan, Russia
}

\begin{abstract}
In the article, the authors present the results of a study of a flat reinforced concrete beamless floor of an existing building. The experiment consisted of loading a slab in span with water tanks. There were 15 loading stages in total, on average $4 \mathrm{kN}$. During the experiment, data was obtained on the relative deformations of concrete and reinforcement in the span and on the support. Also, observations of the growth of vertical deformations and the growth of cracks in the span were introduced.
\end{abstract}

Keywords. In-situ, load test, reinforced concrete slab, cracking.

\section{Introduction}

Currently, most civil buildings are erected from monolithic reinforced concrete directly on the construction site. The advantage of this method of erecting buildings is, mainly, the ability to create almost any geometric shape of the future structure. The connections of the bearing elements of the building (columns, beams, floor slabs) between themselves are rigid, and the design scheme of the building itself is many times statically indeterminate. In particular, a flat monolithic reinforced concrete floor slab is a statically indeterminate system with rigid nodes on supports.

Over time, the magnitude of the load acting on the floor, as well as the physical and mechanical characteristics of concrete and reinforcement can change. For further safe operation of the structure, it is necessary to monitor its technical condition.

To collect information about the floor slab, destructive and non-destructive control methods are used with further verification calculation. There is a large number of works devoted to the study of existing reinforced concrete flat floors with various defects.

The article [1] demonstrates the features of visual control over the state of reinforced concrete structures using computer technology. For this, a special program based on machine learning was created to assess structural damage by the type and pattern of cracks on the surface of the structure. These estimates coincided very closely with the data of computer calculations.

The assessment of damage to reinforced concrete structures by the ultrasonic method is considered in [2]. For testing, we used samples with dimensions of $750 \times 1400 \times 300 \mathrm{~mm}$, reinforced with rods in two directions. Sources and receivers of ultrasonic waves were installed on the edges of the slab. During loading, data was taken from the receiver. Graphs of distortion and scattering of signals from source to receiver in connection with the

${ }^{*}$ Corresponding author: minzianovrustam@gmail.com 
formation and development of cracks were built. Corrosion of concrete and reinforced concrete was studied in [3].

Similar studies were carried out by scientists in the study [4]. In this work, combinations of various methods of non-destructive testing of reinforced concrete slabs were used. On the basis of these data, maps of damage to the slabs were compiled.

Often, damage to reinforced concrete floor slabs is associated with defects that have arisen during construction and installation work.

When constructing buildings from monolithic reinforced concrete, the formation of construction joints, which are not taken into account in the calculation, is inevitable. The calculation of reinforced concrete slabs with construction joints is given in the study [5]. The critical dimensions of construction joints that disrupt the operation of the structure during operation are indicated.

Openings in floor slabs are also inevitable, which may not be taken into account by the project. The influence of openings in slabs on their bearing capacity was estimated in [6]. The dependences of the size and shape of the openings on the bearing capacity are given, the critical dimensions of the openings are indicated.

For reinforced concrete structures, the ratio of long-term and short-term loads is critical, since this has a direct effect on the bearing capacity.

The assessment of the effect of long-term loads and existing cracks on the destruction of a reinforced concrete slab is considered in [7]. The dependences of the crack opening width on the degree of reinforcement corrosion were revealed, and reinforcement corrosion, in turn, on the nature of the destruction of the reinforced concrete slab.

In [8], the influence of longitudinal and transverse reinforcement on the punching characteristics of reinforced concrete slabs is estimated. Samples in the form of slabs with dimensions of $1050 \times 1050 \times 100 \mathrm{~mm}$, reinforced with reinforcement with a diameter of $10 \mathrm{~mm}$ and additional reinforcement with a diameter of $12 \mathrm{~mm}$ in a tensioned zone made of steel with an ultimate strength of $520 \mathrm{MPa}$, were subjected to a concentrated load. Reinforcing bars with a diameter of $8 \mathrm{~mm}$ made of steel with an ultimate strength of $350 \mathrm{MPa}$ were used as transverse reinforcement. Fracture analysis showed that a decrease in the pitch of the transverse rods from 150 to $100 \mathrm{~mm}$ increases the bearing capacity by $23 \%$, and from $150 \mathrm{~mm}$ to $50 \mathrm{~mm}$ - by $36 \%$. The punching shear strength of reinforced concrete flat slabs was also evaluated in [9].

Disturbances in the operation of reinforced concrete flat floor slabs can occur due to their premature loading, for example, due to early removal of the formwork due to the limited construction time. The influence of premature loading of plates is considered in [10]. Specimens of $1100 \times 1100 \times 120 \mathrm{~mm}$ in size with different concrete hardening times were investigated. The dependences of the critical strength of concrete on the punching shear of floor slabs under premature loading are revealed.

In the case when it is impossible to guarantee the bearing capacity of the floor slabs during the operation stage by visual signs, they resort to the method of loading the slab with a static load. This method can provide answers to many questions that have not been studied theoretically yet.

Static load tests of reinforced concrete floor slabs have been carried out by many researchers. In particular, of great interest is the work [11], in which the existing reinforced concrete floor with cracks and deformations was tested. The slab was loaded with layers of sand. As a result of the test, reinforced concrete slabs were revealed that were not subject to further operation.

A similar work was carried out in studies [12] and [13] devoted to the effect of cracks on the bearing capacity of floor slabs.

An important step in the inspection of flat floors is the verification calculation. Since a monolithic reinforced concrete floor slab is a statically indeterminate system, its calculation presents some difficulties. The theoretical grounds for calculating such systems are as follows.

When calculating statically indeterminate structures as elastic systems, it is assumed that structural elements are ideally elastic and their stiffness is constant and does not depend on 
the duration of the load or on its magnitude. Under this condition, the forces in the structural elements can change only as a result of changes in loads, temperature and shrinkage deformations, and the position of the supports.

Most building structures, including reinforced concrete, do not have elastic properties. In structures made of such materials, in addition to elastic ones, inelastic deformations appear, causing irreversible changes in the structural elements, which significantly affect the nature of the distribution of forces. Moreover, this influence can be so significant that the calculation of structures as elastic systems does not even approximately reflect their actual work.

In reinforced concrete structures, as the load increases, a number of significant inelastic changes occur. To a certain extent, reinforced concrete structures work without cracks. Under loads close to normal under normal operating conditions, deformations of linear creep of concrete develop. They redistribute stresses in the section (for example, between compressed reinforcement and compressed concrete), but have little effect on the ratio of curvatures in different sections. In this case, cracks form and develop in the extended zone. When approaching the moment of exhaustion of the bearing capacity in the most stressed sections of the structure, nonlinear creep of concrete develops, affecting the distribution of forces, in short or more significant sections, the adhesion of reinforcement to concrete is broken, and, finally, reinforcement fluidity is observed.

The strength, stiffness and crack resistance of the floor slab are influenced by longitudinal working reinforcement, transverse reinforcement in the punching shear zone, as well as concrete in the compressed and stretched zone.

Various scientists and authors have been involved in the calculation of flat reinforced concrete slabs.

The strength and deformability of flat reinforced concrete floors as a whole were estimated in [14]. A large number of factors are given, the combined effect of which greatly affects the bearing capacity of such structures, and, therefore, requiring increased attention during design.

In [15], the calculation of reinforced concrete slabs by the limit state is proposed using an integrated method without breaking into finite elements based on a radial basis function. The advantage of the developed method is to reduce the time of calculation and analysis, for example, for a grid of $15 \times 15$ nodes - from 5.8 seconds to 0.5 seconds.

The work [16], devoted to analytical methods of analyzing the operation of floor slabs as membranes, is of interest.

Various types of reinforced concrete floors were studied in [17] using a plate element based on high-order computational continua. The advantages of this method are its versatility, the ability to take into account damage, as well as the presence of prestressed reinforcement.

Methods for constructing stress and displacement fields in reinforced concrete slabs are considered in [18]. The proposed algorithm based on the Nielsen criterion, using a rotationfree meshless model and a second-order cone as a strength criterion, is in good agreement with these calculations by other methods.

In work [19], devoted to the study of the distribution of peak shear stress in finite element models of reinforced concrete slabs, recommendations are given for the division of structures into finite elements, as well as recommendations for the sizes of these elements. Taking these recommendations in modeling, it is possible to describe with great accuracy a numerical model that is consistent with real objects.

In reinforced concrete structures, an important component is the adhesion of the reinforcement to the concrete. The work of reinforcement with concrete was studied in [20]. A brand-new model of reinforcement-concrete adhesion was developed.

Probabilistic methods can be used to assess the stress-strain of flat reinforced concrete slabs. Proposals for the use of probabilistic methods for determining the ultimate bearing capacity of floor slabs are given in [21]. 
Shear resistance of plates is under development. A new model for reinforced concrete slabs and floor beams was proposed by scientists in [22]. The advantages of the model are the saving of reinforcement and concrete, as well as an increase in the safety factor of structures. Other authors in [23] also developed new approaches to the calculation of the shear plate, while comparing the theoretical results with experiments.

If there is a need to strengthen the floor, you can use fiber-reinforced concrete. Similar studies were carried out in [24].

Previously, it was believed: while the reinforcement does not flow in any section, the reinforced concrete structure operates under conditions close to those adopted as the basis for calculating the elastic system. It was believed that the redistribution of forces in statically indeterminate reinforced concrete structures occurs only after the appearance of reinforcement yield in any section. It turned out that such a scheme of work is conditional and, as the load increases, does not reflect all the changes that occur in the structures.

With an increase in the load, a number of stages can be noted in the work of a statically indeterminate structure. The first stage is characterized by the work of the structure until cracks appear. After the appearance of cracks in the supporting and spanning sections, their rigidity decreases significantly, the curvature in the areas with cracks increases significantly, and the ratio between the supporting and spanning moments changes (second stage).

With the appearance of inelastic deformations (yield) of the reinforcement in any section, the work of the beam passes into the third stage, which ends with the exhaustion of its bearing capacity. The fluidity of the reinforcement causes a new redistribution of forces, which significantly changes the nature of the structure's operation and leads to the distribution of forces determined by the reinforcement. In particular, in flat slabs, destruction occurs into flat links connected to each other along fracture lines by linear plastic hinges, and turns into a variable system.

\section{Methods}

The object of the study was a monolithic reinforced concrete floor slab without beams of an existing building.

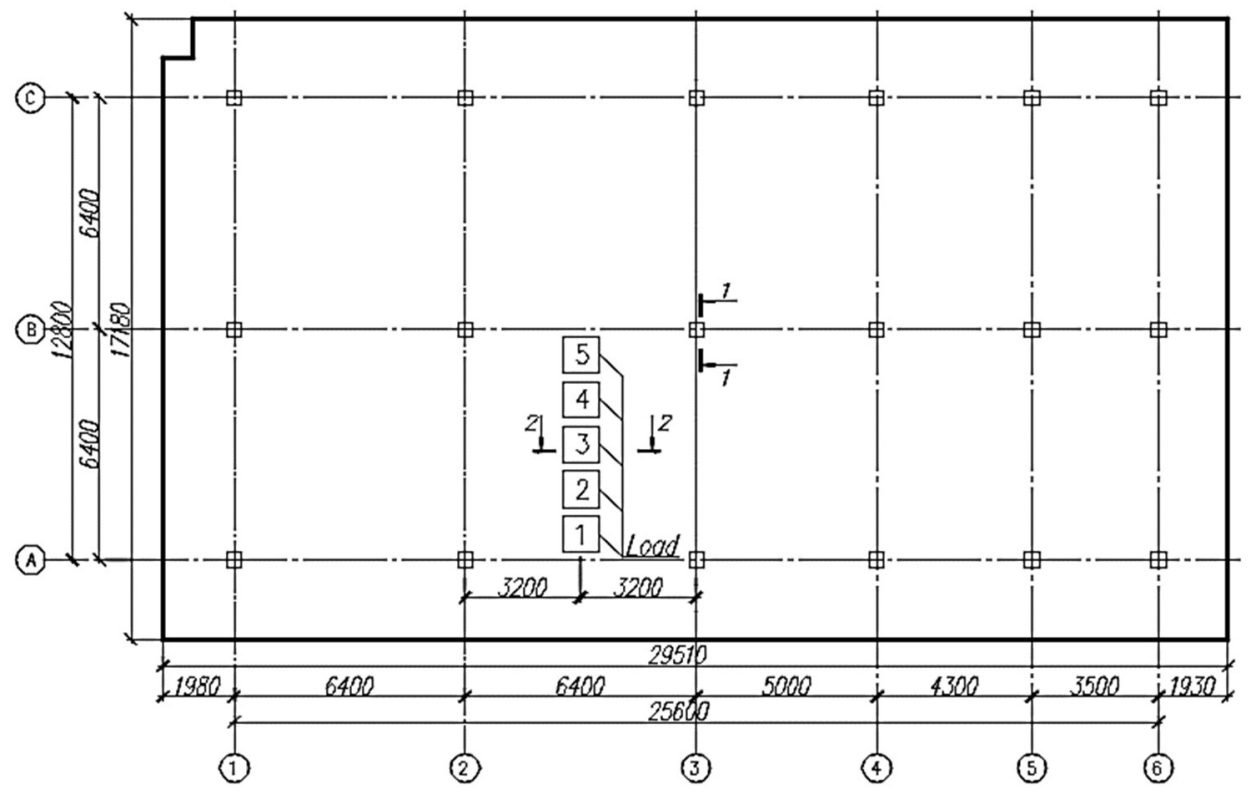

Fig. 1. Slab plan with numbering of load points. 


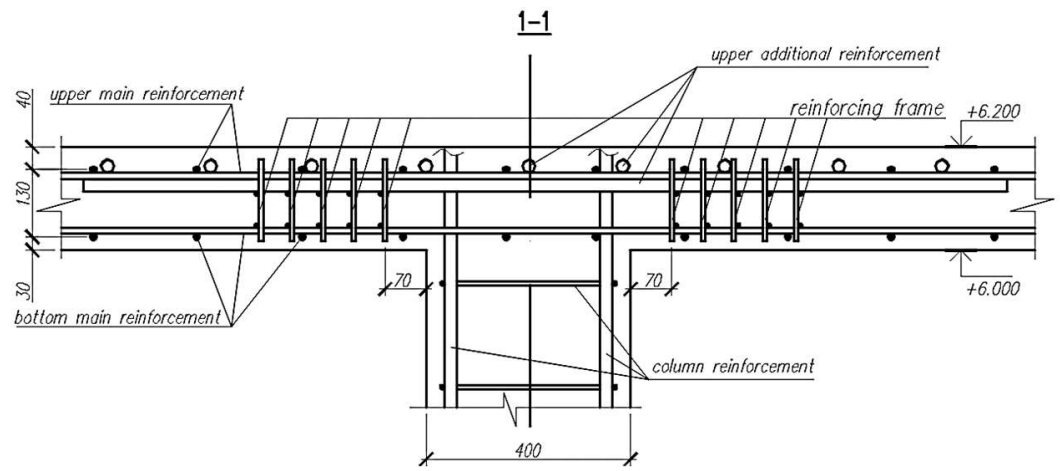

Fig. 2. Reinforcement scheme in the support zone of the slab in section 1-1.

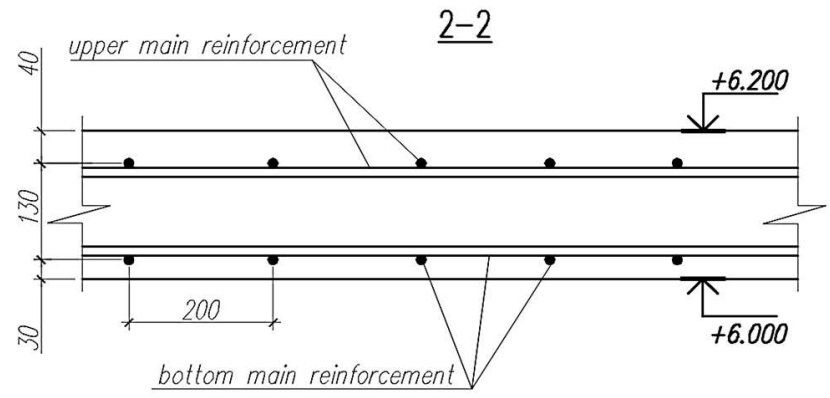

Fig. 3. Reinforcement scheme in the span of the slab in section 2-2.

Before starting work, the design of the frame was studied and the compliance of the frame with the project was checked. At the time of the study, the reinforced concrete frame was 8 years old. Also, before testing the slab, a visual inspection was carried out to identify existing cracks. Several cracks were noted in the lower part of the span of the slab along the digital axes with a maximum opening width of up to $0.1 \mathrm{~mm}$. Also, the authors collected data on the strength of concrete and reinforcement, from which the slab is made.

The floor slab plan is shown in Fig. 1-3. The slab has dimensions in terms of $17180 \times 29510$ $\mathrm{mm}$. The thickness of the slab is $200 \mathrm{~mm}$.

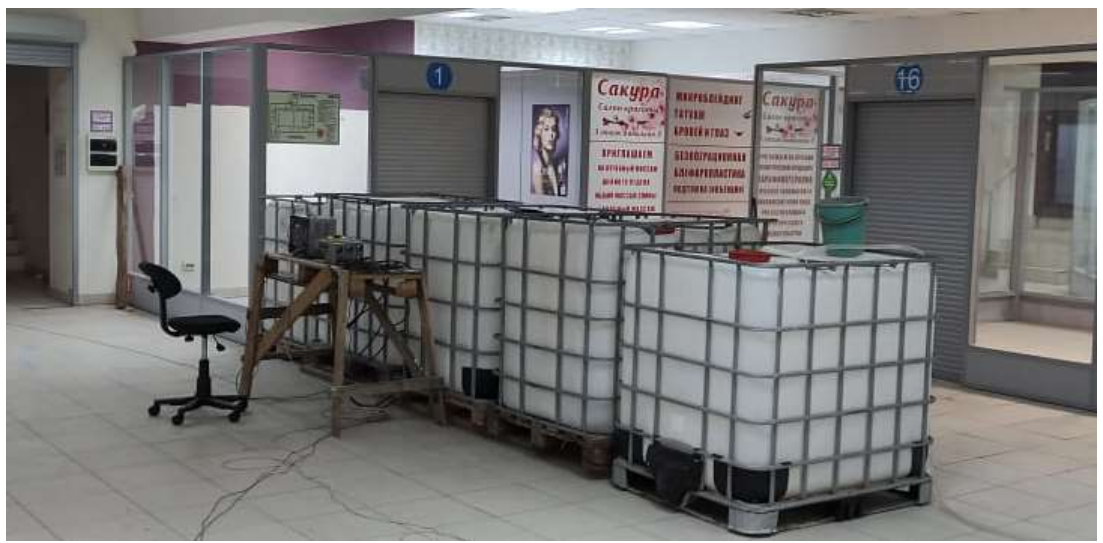

Fig. 4. Floor slab loaded with water tanks.

The slab was loaded in stages, 15 in total; tanks with water were used as the load on the slab. The time between loading steps was 30 minutes. At the beginning of the test, the tanks 
were empty and filled with water as they were loaded. The load on the slab was located in the 2-3/A-B axes as shown in Fig. 1.

At each loading, the calculated bending moment was determined in two planes $M_{x}$ (along the digital axes) and $M_{y}$ (along the letter axes), in the center of the span and on the support in the LIRA SAPR software package. The distribution of moment isofields is shown in Fig. 5.

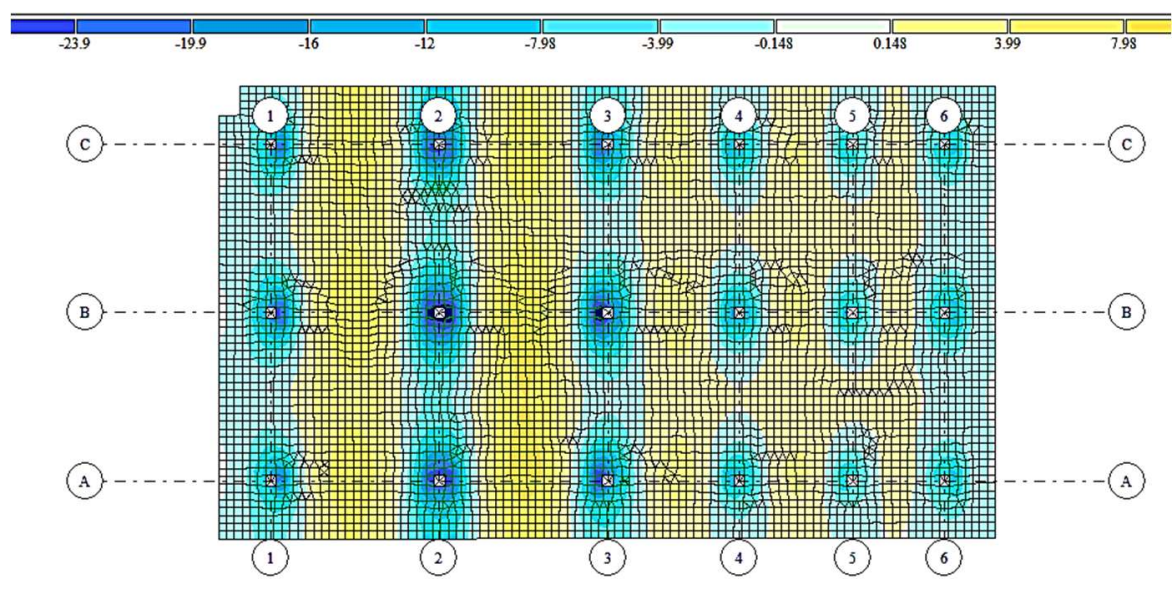

Fig. 5. Bending moment Mx diagram at stage 15 of loading (LIRA SAPR).

After the last $15^{\text {th }}$ stage of the load was applied, the load remained on the slab for 45 days. Control readings for deflections and cracks were taken every 7 days.

The table of load cases is presented below in Table 1 .

Table 1. Loading stages.

\begin{tabular}{|c|c|c|c|c|c|c|c|c|c|}
\hline \multirow{2}{*}{$\begin{array}{l}\text { Loading } \\
\text { stages }\end{array}$} & \multicolumn{5}{|c|}{$\begin{array}{l}\text { Load in places of application } \\
\text { (Fig. 1), kN }\end{array}$} & \multicolumn{2}{|c|}{$\begin{array}{l}\text { Bending moment } \\
\text { in span }\end{array}$} & \multicolumn{2}{|c|}{$\begin{array}{l}\text { Bending moment } \\
\text { on support }\end{array}$} \\
\hline & 1 & 2 & 3 & 4 & 5 & $\begin{array}{c}M_{x} \\
(\mathrm{kN} \cdot \mathrm{m})\end{array}$ & $\begin{array}{c}M_{y} \\
(\mathrm{kN} \cdot \mathrm{m})\end{array}$ & $\begin{array}{c}M_{x} \\
(\mathrm{kN} \cdot \mathrm{m})\end{array}$ & $\begin{array}{c}M_{y} \\
(\mathrm{kN} \cdot \mathrm{m})\end{array}$ \\
\hline 0 & 0 & 0 & 0 & 0 & 0 & 7.46 & 7.63 & -31.83 & -31.48 \\
\hline 1 & 2 & 0 & 0 & 0 & 2 & 7.63 & 7.63 & -32.23 & -31.73 \\
\hline 2 & 2 & 2 & 0 & 2 & 2 & 8.01 & 7.82 & -32.72 & -32.16 \\
\hline 3 & 2 & 2 & 2 & 2 & 2 & 8.34 & 8.16 & -32.98 & -32.42 \\
\hline 4 & 4 & 2 & 2 & 2 & 4 & 8.52 & 8.16 & -33.38 & -32.66 \\
\hline 5 & 4 & 4 & 2 & 4 & 4 & 8.89 & 8.36 & -33.87 & -33.09 \\
\hline 6 & 4 & 4 & 4 & 4 & 4 & 9.23 & 8.69 & -34.13 & -33.35 \\
\hline 7 & 6 & 4 & 4 & 4 & 6 & 9.4 & 8.69 & -34.53 & -33.6 \\
\hline 8 & 6 & 6 & 4 & 6 & 6 & 9.77 & 8.88 & -35.02 & -34.02 \\
\hline 9 & 6 & 6 & 6 & 6 & 6 & 10.12 & 9.22 & -35.27 & -34.28 \\
\hline 10 & 8 & 6 & 6 & 6 & 8 & 10.28 & 9.22 & -35.68 & -34.53 \\
\hline 11 & 8 & 8 & 6 & 8 & 8 & 10.66 & 9.41 & -36.17 & -34.96 \\
\hline 12 & 8 & 8 & 8 & 8 & 8 & 11 & 9.75 & -36.43 & -35.22 \\
\hline 13 & 10 & 8 & 8 & 8 & 10 & 11.17 & 9.75 & -36.83 & -35.46 \\
\hline 14 & 10 & 10 & 8 & 10 & 10 & 11.54 & 9.94 & -37.32 & -35.89 \\
\hline 15 & 10 & 10 & 10 & 10 & 10 & 11.88 & 10.28 & -37.57 & -36.15 \\
\hline
\end{tabular}

To determine the relative deformations in the span and on the support of the slab, strain gauges were installed. The locations of the strain gauges are marked in Fig. 6-8. Strain gauges installed on concrete and on reinforcement had different dimensional bases equal to $50 \mathrm{~mm}$ and $20 \mathrm{~mm}$. 

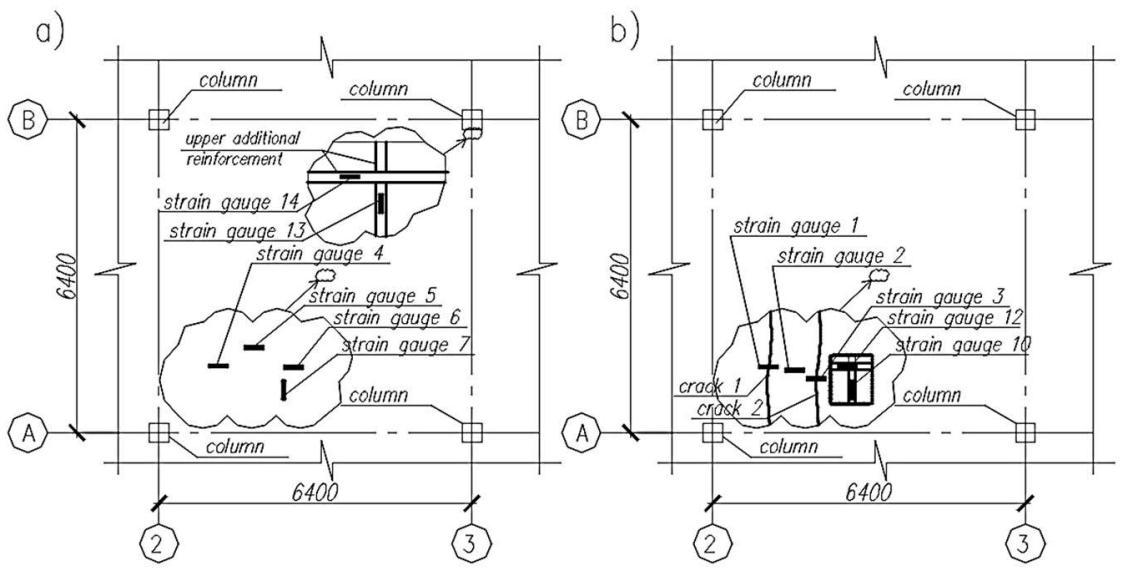

Fig. 6. Locations of strain gauges on the floor slab: $\mathrm{a}$ - top view; $\mathrm{b}$ - bottom view.

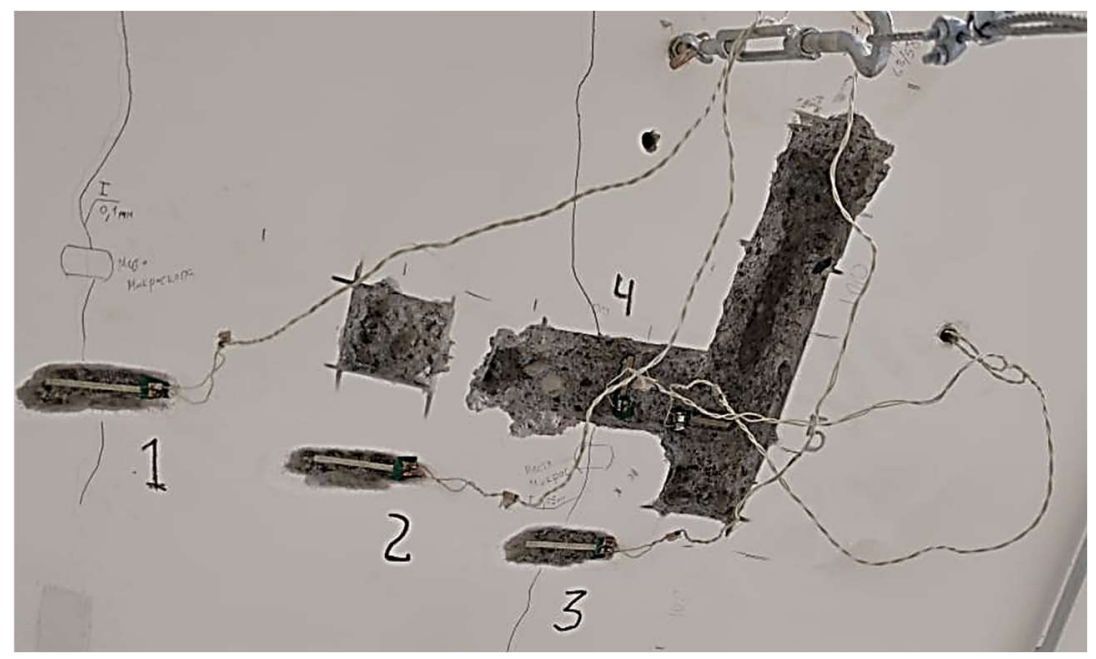

Fig. 7. Locations of strain gauges from below on the floor slab in the span.

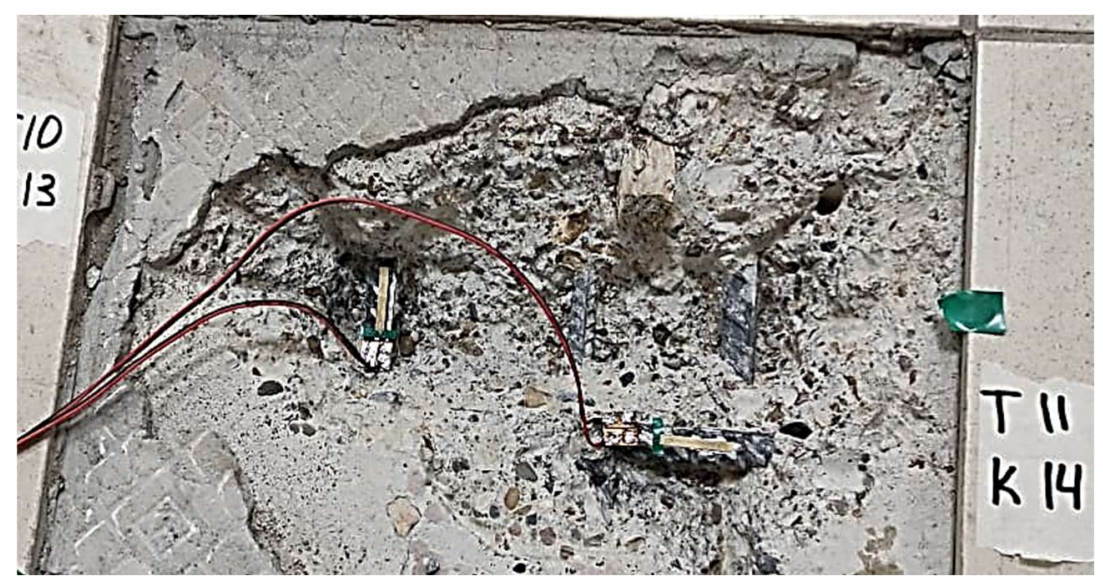

Fig. 8. Locations of strain gauges on top of the floor slab on the support. 
Cracks №1 and №2 were also monitored in the span (Fig. 6). Before loading, crack №1 had an opening width of $0.1 \mathrm{~mm}$, and crack №2 had an opening width of $0.05 \mathrm{~mm}$. At each stage of loading, the crack opening width was measured using a microscope.

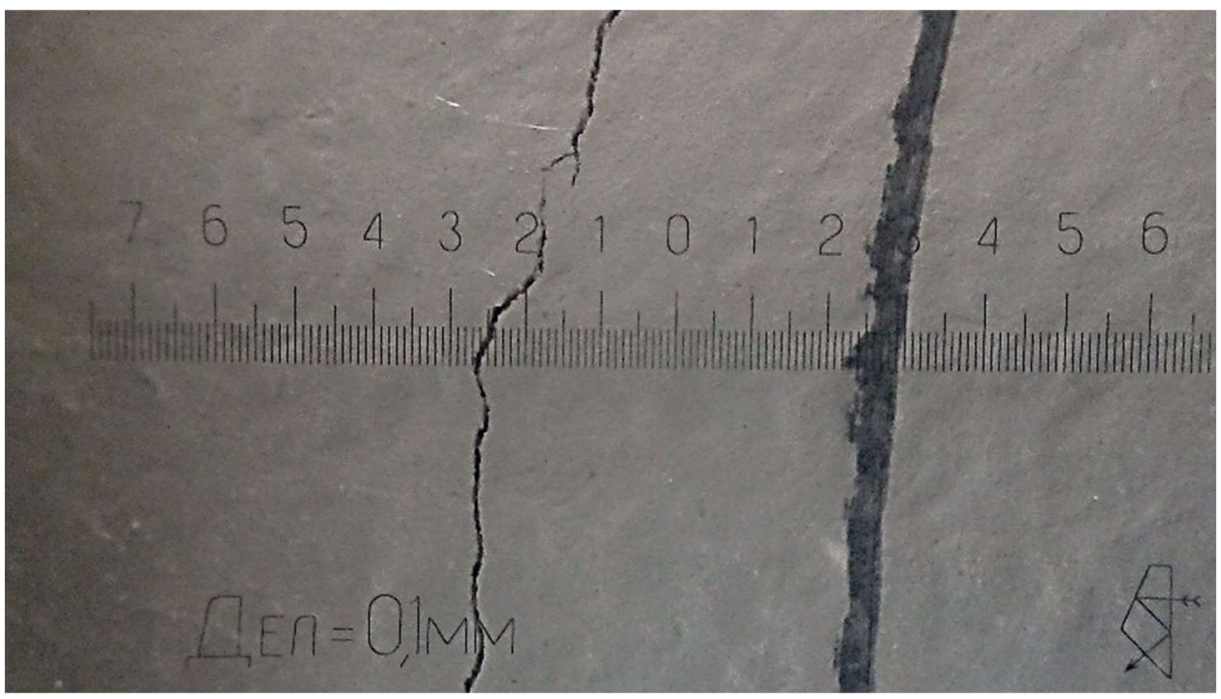

Fig. 9. Crack №1 through a microscope.

To determine the vertical deformations in the slab at points 1 and 2 (Fig. 10), indicators were installed (Fig. 11). The indicators were installed on the floor of the lower floor, which was not influenced during the experiment. To transfer the displacements from the slab to the indicators at points 1 and 2, loads were suspended from the slab using steel cables. With this method of measuring displacements, in order to maintain accuracy, the air temperature was controlled in the room throughout the experiment.

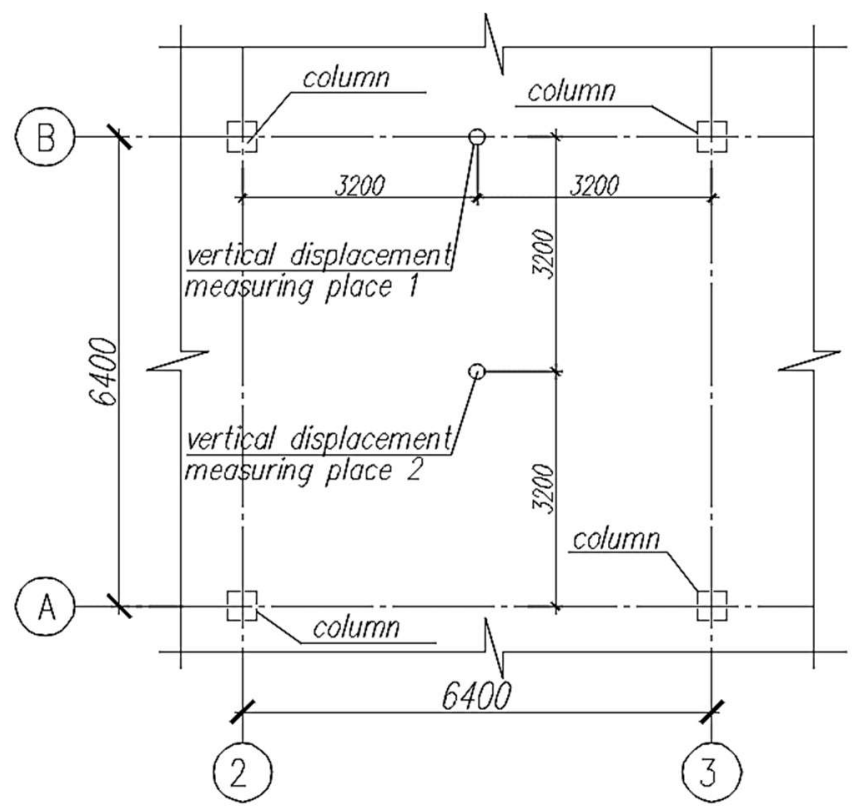

Fig. 10. Locations of indicators of vertical displacements №1 and №2 on the plan. 


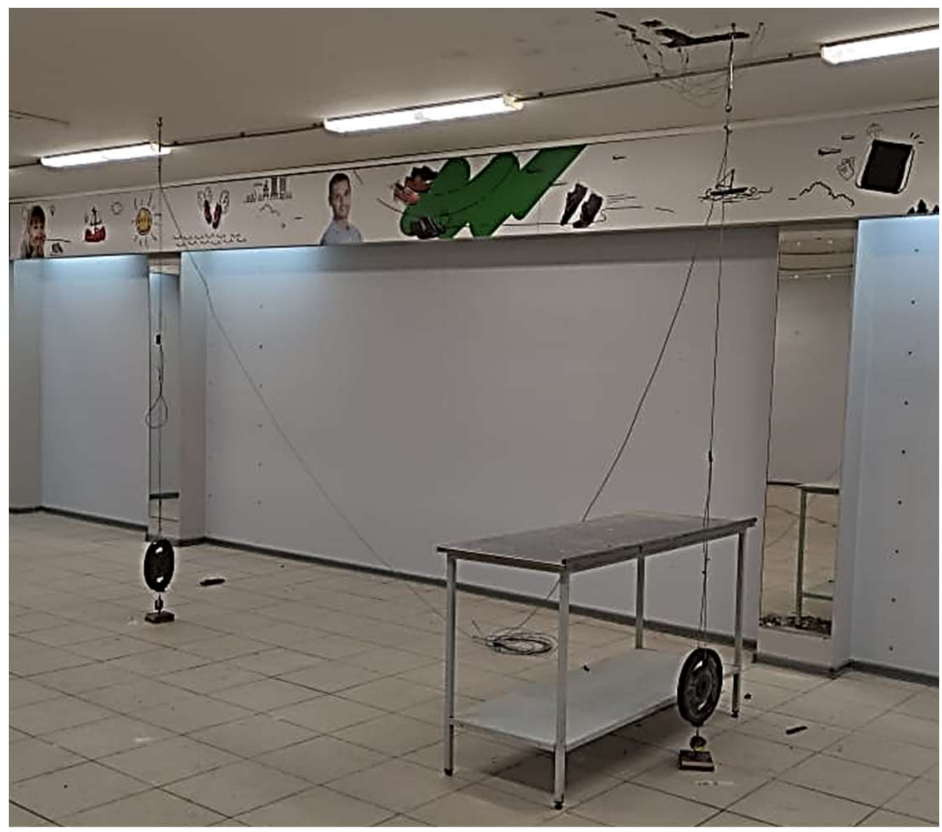

Fig. 11. Places of indicators of vertical displacements under the floor slab.

\section{Results}

According to the results of the physical experiment, the authors obtained the following graphs and dependencies.

Since the loading was carried out in stages, gradually loading parts of the slab from the supports to the span, the bending moment in the slab, which is the main factor in the study, may not change linearly. For a visual assessment of the change in the value of the bending moment in the span and on the support and comparison with further results, the graphs are shown in Fig. 12, 13.

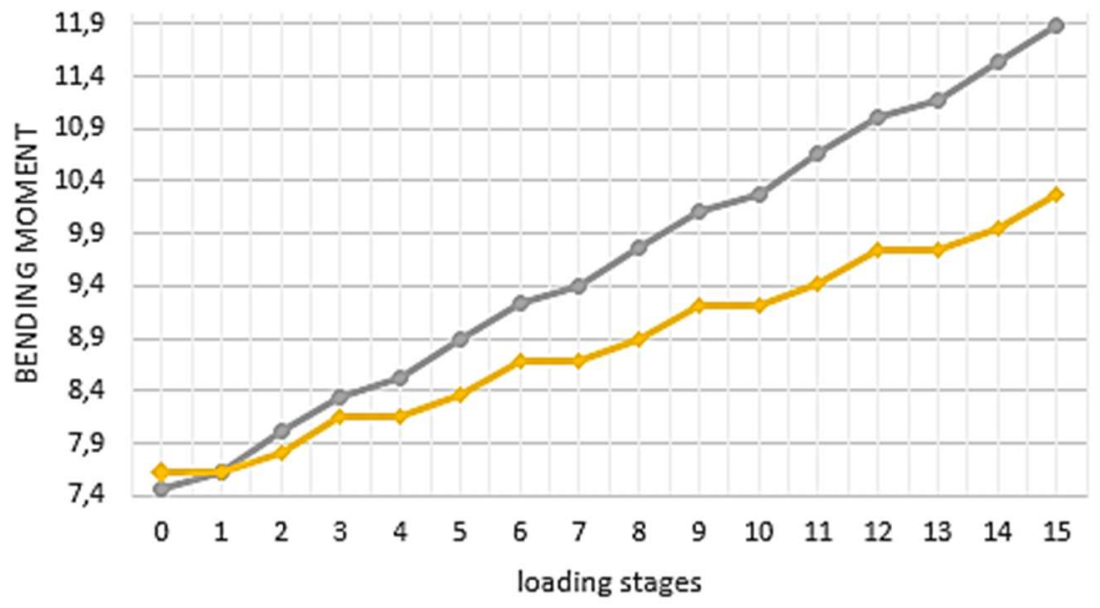

$\Longrightarrow$ Bending moment $M x \quad \leadsto$ Bending moment My

Fig. 12. Bending moments Mx and My in span. 


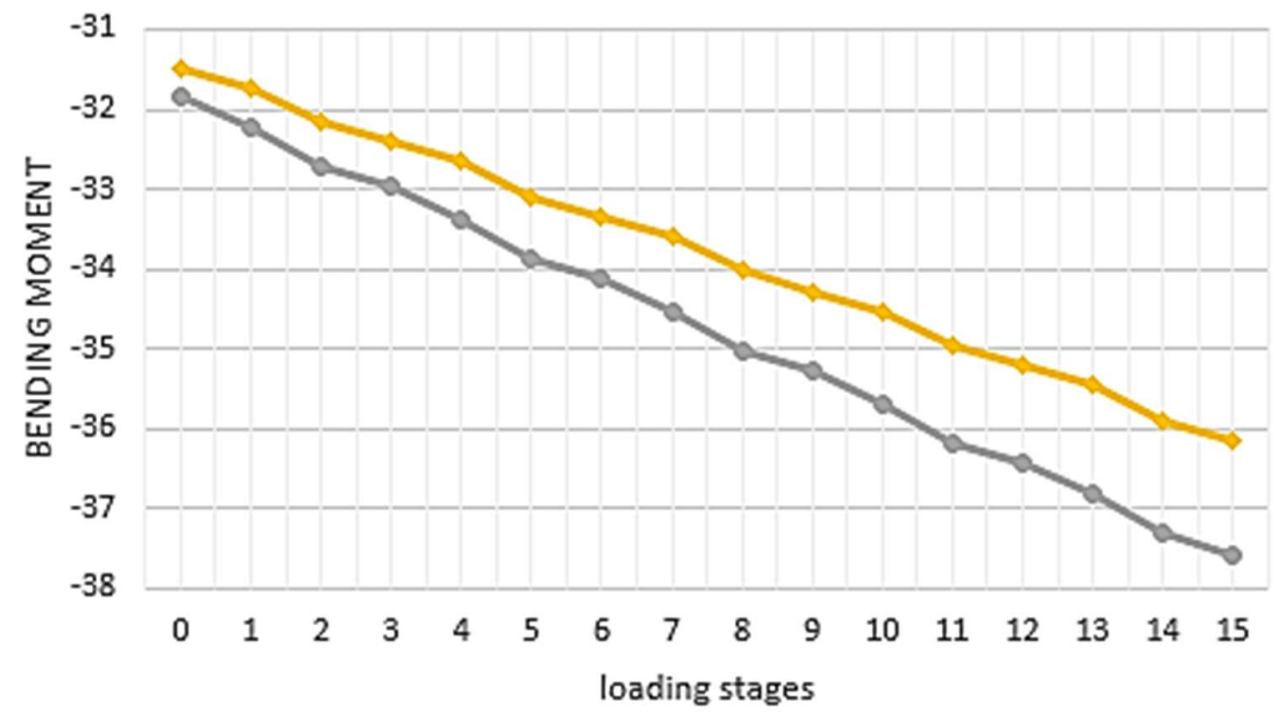

$\longrightarrow$ Bending moment $\mathrm{Mx} \quad \leadsto$ Bending moment $\mathrm{My}$

Fig. 13. Bending moments $\mathrm{Mx}$ and $\mathrm{My}$ on the support.

The graphs (Fig. 14, 15) of the dependence of the relative deformations in the lower zone of the slab on concrete (strain gauges № 1-3) and on reinforcement (strain gauges № 10, 12) have been built.

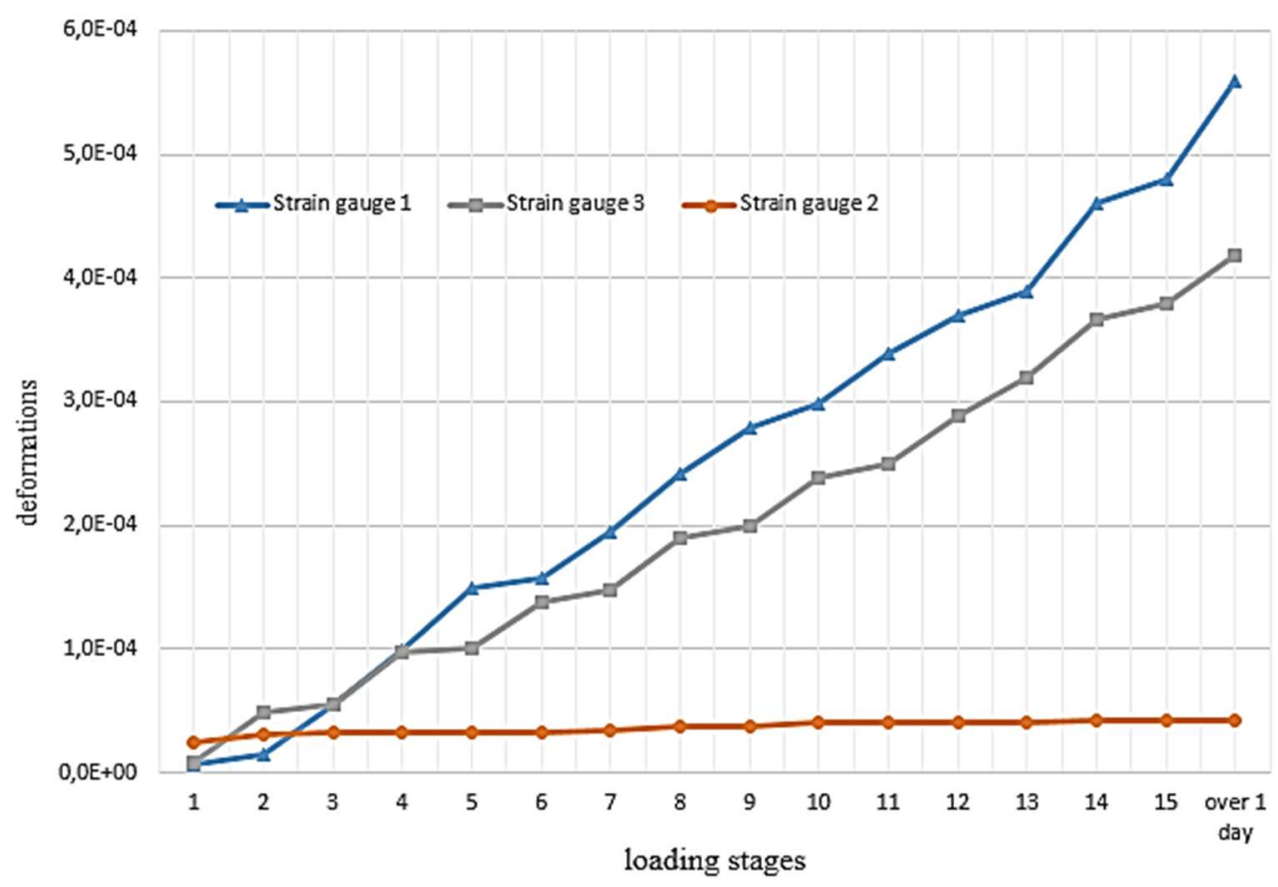

Fig. 14. Graph of changes in relative deformations in concrete under the slab. 


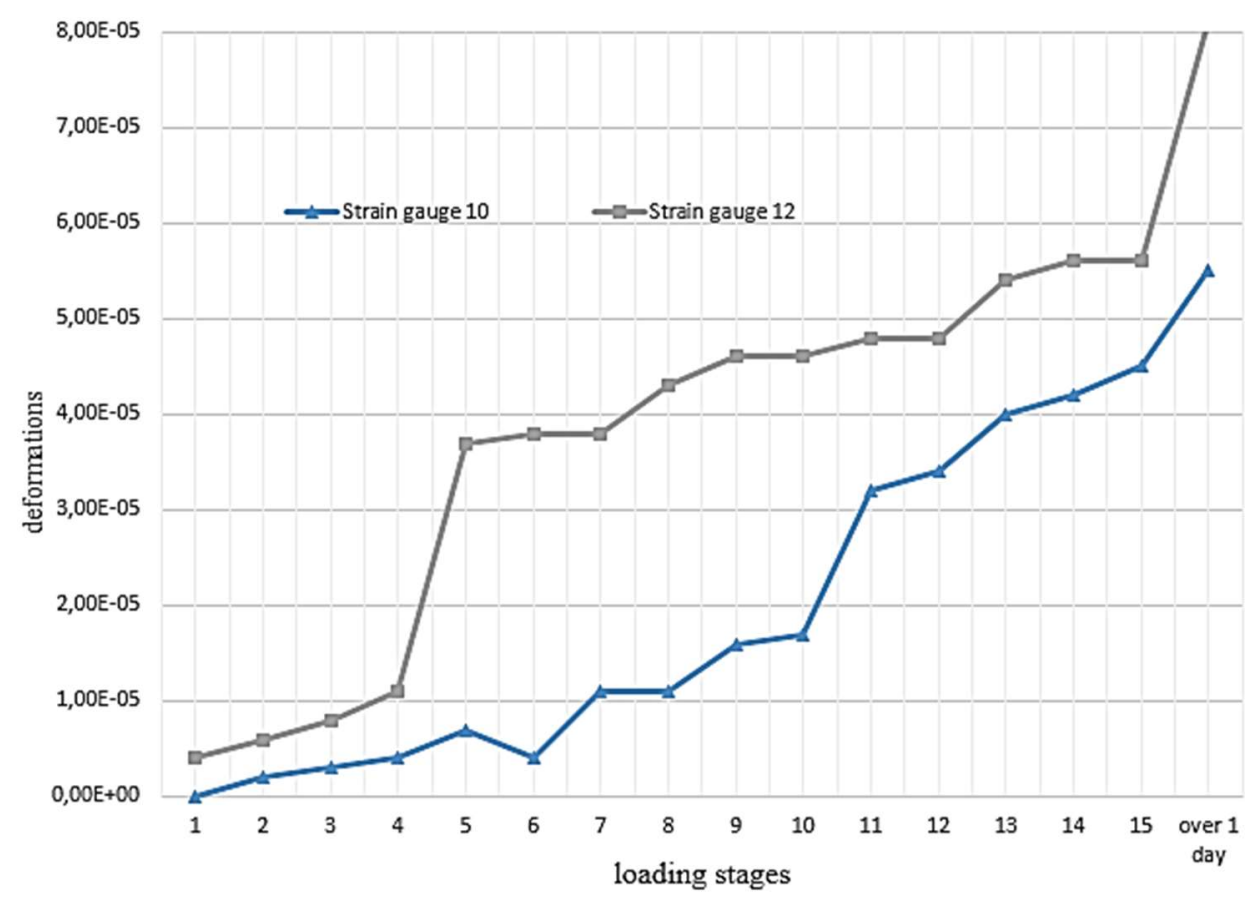

Fig. 15. Graph of changes in relative deformations in tensile reinforcement under the slab.

Graphs (Fig. 16, 17) of the dependence of the relative deformations in the upper zone of the slab on concrete (strain gages № 4-7) and on the reinforcement located above the support (strain gages №13, 14) have been built.

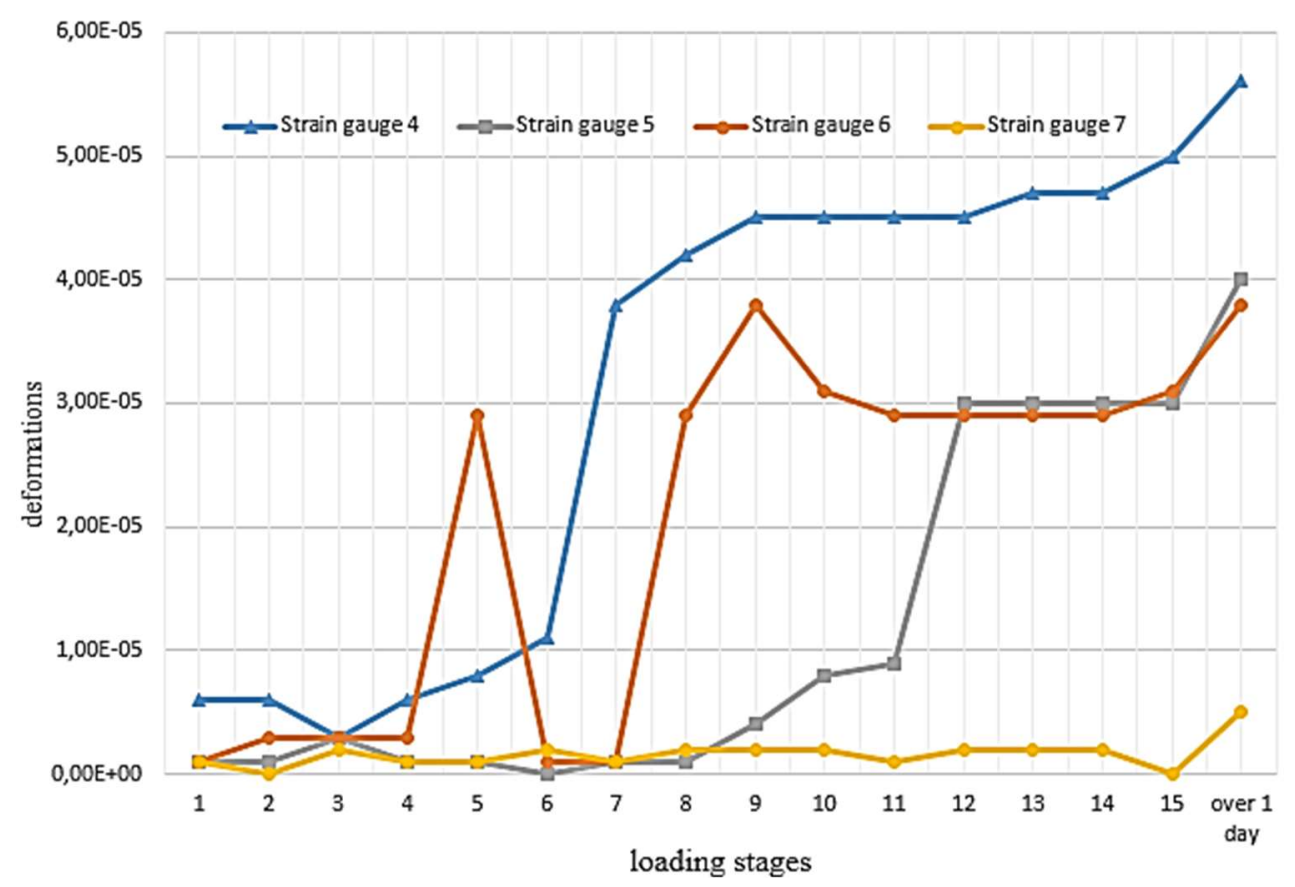

Fig. 16. Graph of changes in relative deformations in concrete above the slab. 


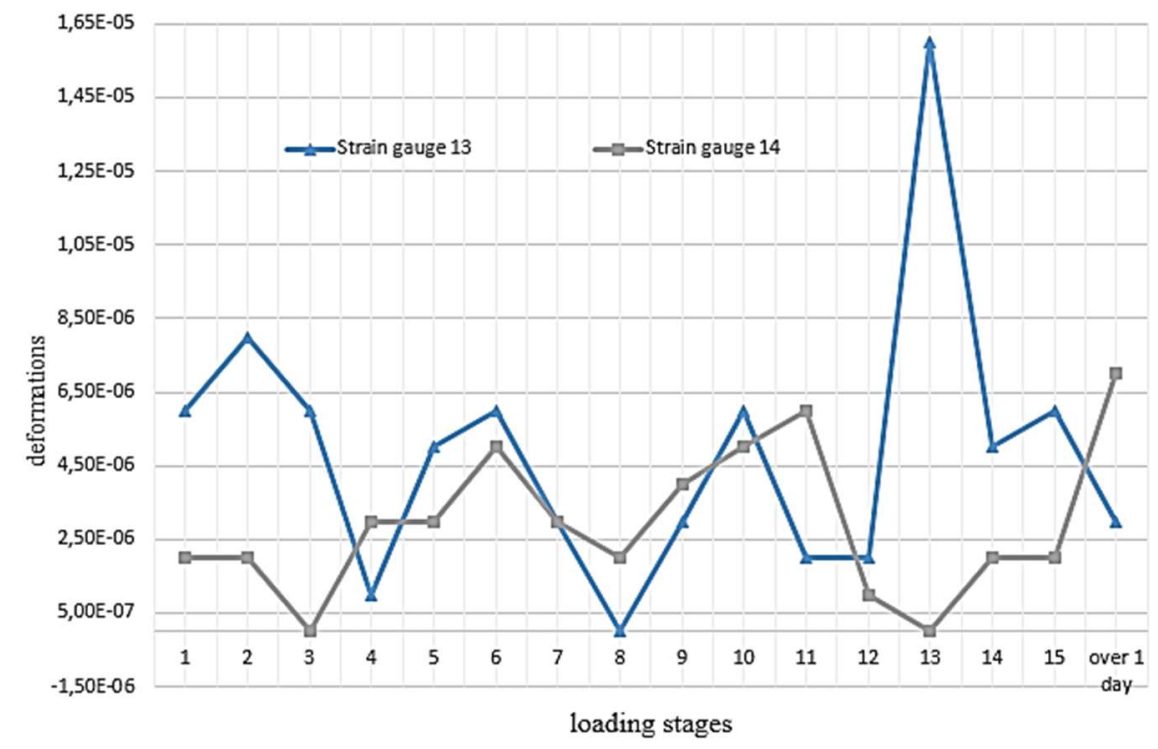

Fig. 17. Graph of changes in relative deformations in tensile reinforcement above the support.

Below is a graph of the vertical displacements of the slab at points 1 and 2 (Fig. 18).

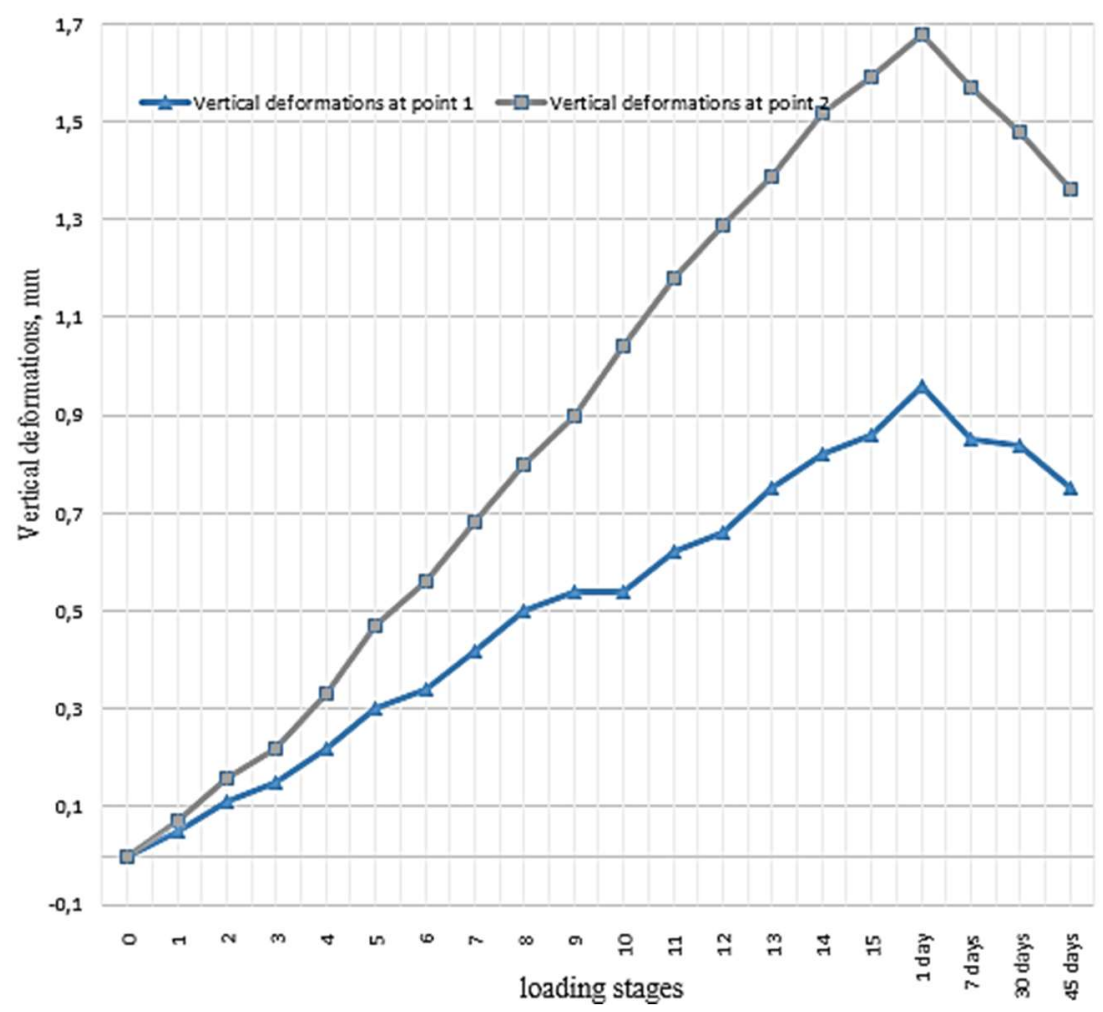

Fig. 18. Graph of vertical deformations of the slab.

Below is the load-width graph for cracks 1 and 2 (Fig. 19). 


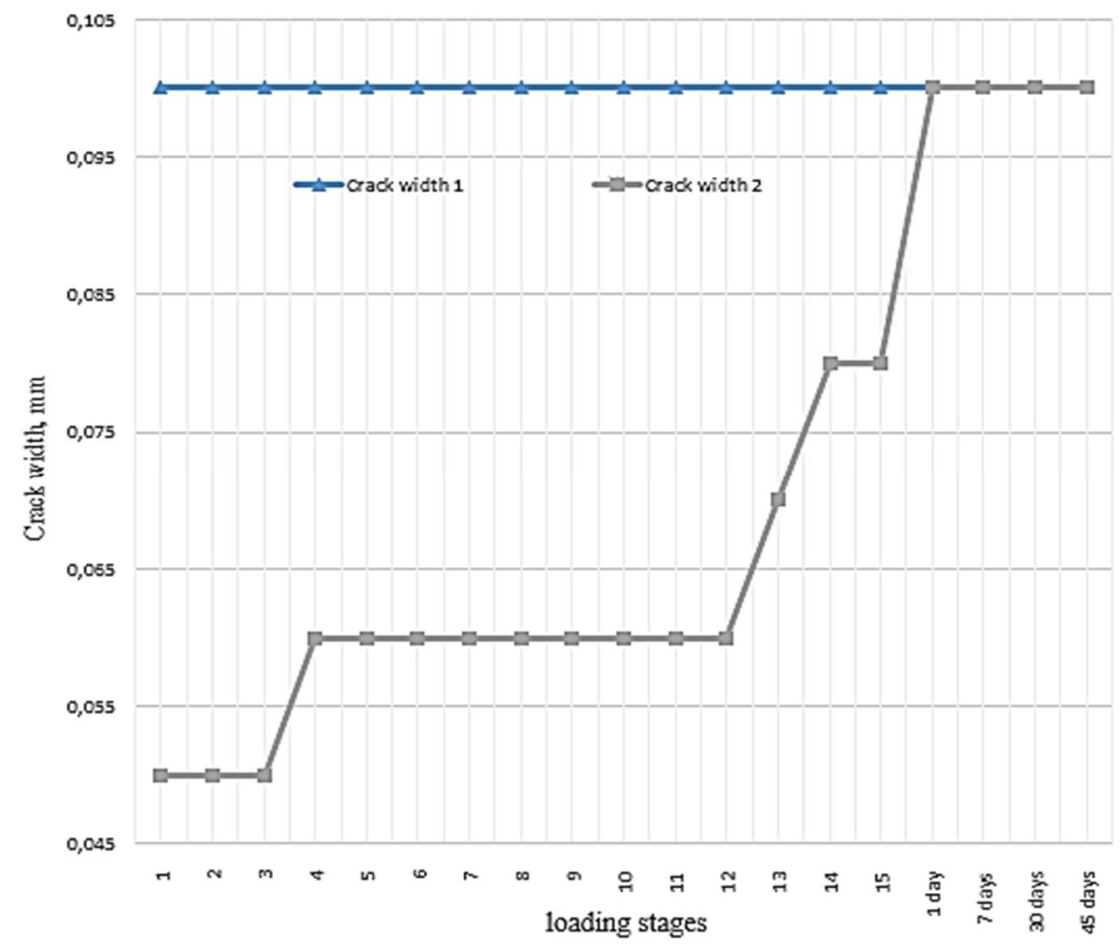

Fig. 19. Graph of changes in the width of cracks 1 and 2 at all stages of loading.

\section{Discussion}

Strain gauges №1 and №3, installed in the span, in the tensile zone of concrete, on cracks, show a linear increase in relative deformations with increasing load. In this case, the proportionality coefficient ranges from $3 \cdot 10-5$ to $4 \cdot 10-5$. Strain gauge №1 grows faster than strain gauge №3, the difference between relative deformations at the highest load is $25 \%$. However, visually, the width of crack №1 (on which gauge №1 is installed) did not change during the experiment, while the width of crack №2 (on which strain gauge №3 is installed) increased. This, at first glance, discrepancy can be explained by the theory of A. Griffith, according to which a larger crack has more surface energy released and redistributed into adjacent fibers of the material. We assume that with a further increase in the load, there would be a sharp increase in the opening width of crack №1 with the formation of new surfaces.

Strain gauge №2, installed in the span, in the tensile zone of concrete, in the area between the cracks, as expected, does not show any increase or decrease in relative deformations. Strain gauge №2 is used to check the adequacy of the experiment being carried out, and it is confirmed.

Strain gauges №4 (above the strain gauge №1) and №6 (above the strain gauge №3) are installed in the span, in the compressed zone of concrete, above the cracks in the tension zone. In general, their readings are consistent with the readings of strain gauges №1 and №3, the difference is also within 25\%. However, strain gauge №6 at test stage №4 has a sharp jump in relative compression deformations, and at stage №5 - the same sharp jump in the reduction of these deformations. In all likelihood, this behavior is also consistent with the theory of A. Griffith, but we could not find precise evidence.

Strain gauge №7, installed in the span, in the compressed zone of concrete, above the section without a crack, along the line of the load, as expected, does not show any increases 
or decreases in relative deformations. By analogy with strain gauge №2, it is used to check the adequacy of the experiment, and it is again confirmed.

Strain gauges №10 (along the line of action of the load) and №12 (perpendicular to the line of action of the load), installed in the span on the reinforcement in the stretched zone, have a linear character of growth of relative deformations. In both cases, the proportionality coefficient is 4·10-6. However, the relative deformations of the strain gauge №12 are greater than that of the strain gauge №10 by $30 \div 35 \%$, and this is also consistent with the theory of operation of reinforced concrete bent structures. The reinforcement at the strain gauge №12 is installed perpendicular to the line of the load action and, accordingly, perceives more force than the reinforcement installed along the line of the load action (on which the strain gauge №10 is installed).

Strain gauges №13 (along the line of the load action) and №14 (perpendicular to the line of action of the load), installed on the support on the reinforcement in the compressed zone, have an abrupt operation. The relative deformations grow and fall, while the rate of these changes is uneven. This work can be explained from the point of view of the theory of calculating statically indeterminate reinforced concrete systems. The stiffness of the support zone is greater than the stiffness of the flying zone, and at certain moments the support zone can take on part of the efforts of the flying zone. Certain moments are understood as the movement of a short-term load from the span to the support area, and vice versa. The test we conducted was of an approximate character, when the outermost tanks with water were first loaded, then the middle ones and at the end - the central one, that is, the load moved from the supports to the span. In this state, the load was maintained for 10 minutes, during which time part of the forces from the span was transferred to the support, loading it and increasing the relative deformations.

The growth of vertical deformations shown by the vertical displacement indicators is linear and, in general, is consistent with the nature of the plate loading.

The constant movement of a short-term load (which is especially typical for shopping malls) has a decisive effect on the operation of reinforced concrete statically indeterminate systems, and under certain circumstances, or with a certain combination of short-term loads, or when this load is moved (that is, when it is not static) there is an instant release of the energy of the surface of the material with the formation of new surfaces in the form of cracks, as well as with an increase in deflections due to a decrease in the rigidity of individual sections of the structure.

\section{Conclusions}

1. A review of studies on the operation of flat reinforced concrete floor slabs has been completed. The author's methods of testing slabs at the stage of operation are considered.

2. Experimental loading of the existing floor slab with a strip load was carried out. The plate was prepared for testing: strain gauges and deflection meters were installed.

3. The test results were obtained and processed, the graphs of the dependences of the relative deformations on the loading were compiled.

4. As a result, it was revealed that the greatest danger for flat reinforced concrete floor slabs is represented by short-term displacement loads.

\section{References}

1. R. Davoudi, G.R. Miller, J.N. Kutz. Data-driven vision-based inspection for reinforced concrete beams and slabs: Quantitative damage and load estimation, Aut Con 96, 292309 (2018). DOI: 10.1016/j.autcon.2018.09.024. 
2. F. Moradi-Marani, P. Rivard, C.-P. Lamarche, S.A. Kodjo. Evaluating the damage in reinforced concrete slabs under bending test with the energy of ultrasonic waves, Con Build Mat 73, 663-673 (2014). DOI: 10.1016/j.conbuildmat.2014.09.050.

3. I. Mirsayapov, S. Yakupov, Majd Hassoun. About concrete and reinforced concrete corrosion. DOI: 10.1088/1757-899X/890/1/012061/.

4. H. Rathod, R. Gupta. Two-dimensional non-destructive testing data maps for reinforced concrete slabs with simulated damage, Data in Bried 25, 104127 (2019). DOI: 10.1016/j.dib.2019.104127.

5. T.W. Jensen, P.N. Poulsen, L.C. Hoang. Limit analysis of reinforced concrete slabs with construction joints, Eng Struct 205, 110062 (2020). DOI: 10.1016/j.engstruct.2019.110062.

6. D. Mostofinejad, N.J. Ali Naderi, A. Mostofinejad, M. Salehi. Effects of openings on the punching shear strength of reinforced concrete slabs, Structures 25, 760-773 (2020). DOI: 10.1016/j.istruc.2020.03.061.

7. Z. Gao, R.Y. Liang, A.K. Patnaik. Effects of sustained loading and pre-existing cracks on corrosion behavior of reinforced concrete slabs, Con Build Mat 124, 776-785 (2016). DOI: 10.1016/j.conbuildmat.2016.08.010.

8. R.T.S. Mabrouk, A. Bakr, H. Abdalla. Effect of flexural and shear reinforcement on the punching behavior of reinforced concrete flat slabs, Alexandria Eng Journal 56, 591-599 (2017). DOI: 10.1016/j.aej.2017.05.019.

9. I. Mirsayapov, G. Nikitin, M. Khanbekov. Strength of reinforced concrete flat slabs for punching, IOP Conf. Ser.: Mater. Sci. Eng. 890, 012076 (2020). DOI: 10.1088/1757899X/890/1/012076.

10. I.G. Shaaban, A.H. Hosni, W.M. Montaser, M.M. El-Sayed. Effect of premature loading on punching resistance of reinforced concrete flat slabs, Case Studies in Con Mat 12, e00320 (2020). DOI: 10.1016/j.cscm.2019.e00320.

11. M.A. Saleem, S. Abbas, M.L. Nehdi. Assessment of reinforced concrete slabs using insitu load testing: A case study, Journal of Build Eng 25, 100844 (2019). DOI: 10.1016/j.jobe.2019.100844.

12. S. Das, S. Dutta, D. Adak, S. Majumdar. On the crack characterization of reinforced concrete structures: Experimental and data-driven numerical study, Structures 30, 134145 (2021). DOI: 10.1016/j.istruc.2020.12.069.

13. G.S. Ferreira, R.L. Pimentel, F.S. Barbosa. Evaluation of two crack models for reinforced concrete one-way slabs subjected to bending by means of modal tests, Structures $\mathbf{2 8}$, 2013-2022 (2020). DOI: 10.1016/j.istruc.2020.10.025.

14. S. Woliński. Robustness and Vulnerability of Flat Slab Structures, Pro Eng. 193, 88-95 (2017). DOI: 10.1016/j.proeng.2017.06.190.

15. Phuc L.H. Ho, Canh V. Le, Tran-Cong T. Limit state analysis of reinforced concrete slabs using an integrated radial basis function based mesh-free method, Applied Mathematical Modelling 53, 1-11 (2018). DOI: 10.1016/j.apm.2017.08.006.

16. S. Wang, S.-B. Kang, Q.-L. Fu, J. Ma, P. Ziolkowski. Analytical approach for membrane action in laterally-restrained reinforced concrete square slabs under uniformly distributed loads, Journal of Build Eng. 41, 102427 (2021). DOI: 10.1016/j.jobe.2021.102427.

17. A. Moyeda, J.F. Comput. Multiscale analysis of solid, waffle, ribbed and hollowcore reinforced concrete slabs, Methods Appl Mech Eng 348, 139-156 (2019). DOI: 10.1016/j.cma.2019.01.022.

18. V. Le Canh, L.H. Ho Phuc, H. Nguyen Phuong, Q. Chu Thang. Yield design of reinforced concrete slabs using a rotation-free meshfree method, Eng Analysis with Boundary Elem 20, 231-238 (2015). DOI: 10.1016/j.enganabound.2014.09.001. 
19. Eva O.L. Lantsoght, Ane de Boer, Cor van der Veen. Distribution of peak shear stress in finite element models of reinforced concrete slabs, Eng Struct 148, 571-583 (2017). DOI: 10.1016/j.engstruct.2017.07.005.

20. I. Mirsayapov, R. Minzianov. Rebar movement in seals under static loading, IOP Conf. Ser.: Mater. Sci. Eng. 890, 012073 (2020). DOI: 10.1088/1757-899X/890/1/012073.

21. A.H. Arshian, G. Morgenthal. Probabilistic assessment of the ultimate load-bearing capacity in laterally restrained two-way reinforced concrete slabs, Eng Struct 150, 5263 (2017). DOI: 10.1016/j.engstruct.2017.07.035.

22. J.-M. Bairán, J.R. Casas. Safety factor calibration for a new model of shear strength of reinforced concrete building beams and slabs, Eng Struct 172, 293-303 (2018). DOI: 10.1016/j.engstruct.2018.06.033.

23. L. Henze, G.A. Rombach, M. Harter. New approach for shear design of reinforced concrete slabs under concentrated loads based on tests and statistical analysis, Eng Struct 219, 110795 (2020). DOI: 10.1016/j.engstruct.2020.110795.

24. O. Radaikin, L. Sharafutdinov. Reinforced concrete beams strengthened with steel fiber concrete, IOP Conf. Ser.: Mater. Sci. Eng. 890, 012045 (2020). DOI: 10.1088/1757899X/890/1/012045. 